\title{
NUMERICAL MODELING OF BURN WOUND FORMATION PROCESS
}

\author{
M. Jasiński
}

Department of Strength of Materials and Computational Mechanics, Silesian University of Technology, Poland (marek.jasinski@ polsl.pl)

\begin{abstract}
In the paper the numerical analysis of thermal processes proceeding in the biological tissue is presented. The tissue is subjected to the external heat flux and $2 D$ problem is taken into account. Perfusion rate is treated as dependent on tissue injury which is estimated on the basis of Arrhenius integral. On the basis of tissue damage fraction the burn wound formation process is analyzed. At the stage of numerical realization the boundary element method is used. In the final part of the paper the example of numerical simulation is shown.
\end{abstract}

Keywords: bioheat transfer, Pennes equation, Arrhenius scheme, boundary element method

\section{INTRODUCTION}

It is well-known that a rise in the temperature of biological tissue can cause immediate irreversible damage to the tissue. When the temperature reaches $60{ }^{\circ} \mathrm{C}$ to $65^{\circ} \mathrm{C}$, the proteins become denatured and tissue necrosis can be expected. After the temperature rises above $100{ }^{\circ} \mathrm{C}$, water in the tissue changes its phase from liquid to steam, increasing interstitial pressure until the pressure within the tissue exceeds the strength of confinement by the tissue architecture, resulting in explosive vaporization and thrombosis. At over $150{ }^{\circ} \mathrm{C}$ the proteins are broken down, releasing hydrogen, nitrogen and oxygen, and leaving a layer of carbonization

Thus, when the burn wound is formed the temperature elevation and thermal damage can dynamically change the thermal distribution during coagulation by altering thermophysical properties of tissue. Special attention in this field is dedicated to the changes in perfusion that accompany necrosis. Such kind of processes are usually modeled by the so-called Arrhenius injury integral in which the reaction rate increases exponentially with the temperature.

In the current paper the tissue is regarded as a homogeneous domain in which heat transfer is assumed to be transient and two - dimensional. Mathematical description of the processes proceeding in the tissue is based on the Pennes equation with perfusion rate coefficient dependent on tissue necrosis, while the remaining thermal parameters are regarded as constant values.

The knowledge of the temperature distribution, degree of the tissue injury and value of the perfusion rate allow to estimate the depth of the burn wound as well as the value of the tissue damage fraction corresponding to respective zones in which different effects inducted by the thermal impulse are occurred. 


\section{GOVERNING EQUATION}

Transient heat transfer in biological tissue domain is described by the Pennes equation in the form $[1,3-6,8-10]$

$$
\mathbf{x} \in \Omega: \quad c \dot{T}=\lambda T_{, i i}+Q_{V}
$$

where $\lambda\left[\mathrm{Wm}^{-1} \mathrm{~K}^{-1}\right]$ is the thermal conductivity, $c\left[\mathrm{Jm}^{-3} \mathrm{~K}^{-1}\right]$ is the volumetric specific heat, $Q_{V}\left[\mathrm{Wm}^{-3}\right]$ is the internal heat source, while $T=T(\mathbf{x}, t)$ and $\dot{T}$ denotes a time derivative.

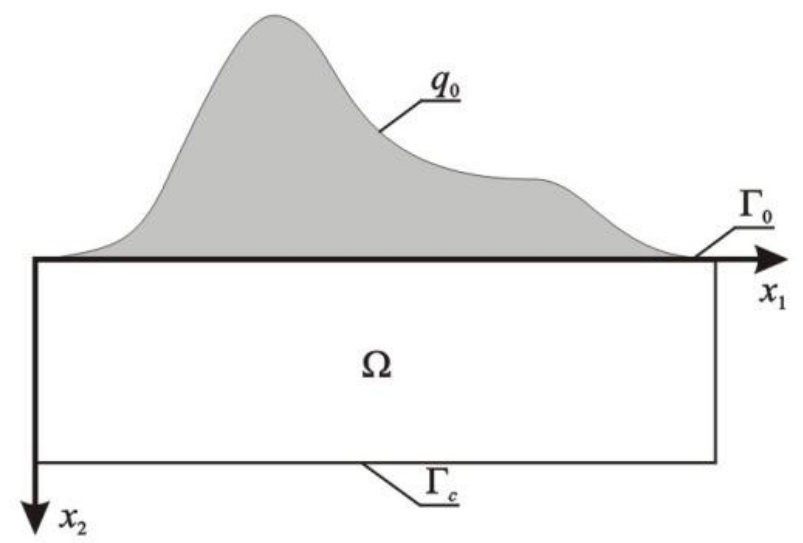

Figure 1. Domain considered

The internal heat source is defined as the sum of the metabolic and perfusion heat sources. The metabolic heat source is assumed as a constant value while the perfusion heat source is in the form

$$
Q_{\text {perf }}=c_{B} G_{B}\left(T_{B}-T\right)
$$

where $G_{B}\left[\left(\mathrm{~m}^{3} \mathrm{blood} / \mathrm{s}\right) /\left(\mathrm{m}^{3}\right.\right.$ tissue $\left.)\right]$ is the blood perfusion coefficient, $c_{B}\left[\mathrm{Jm}^{-3} \mathrm{~K}^{-1}\right]$ is the volumetric specific heat of blood and $T_{B}$ is the artery temperature.

According to the necrotic changes in tissue, the blood perfusion coefficient is defined as $[1,5]$

$$
G_{B}=G_{B}(\theta)=G_{B 0} f(\theta)
$$

where $G_{B O}$ is the initial perfusion coefficient and the $\theta$ corresponds to tissue injury integral [1, $3-5]$

$$
\theta(\mathbf{x})=\int_{0}^{t^{F}} A \exp \left[-\frac{\Delta E}{R T}\right] \mathrm{d} t
$$

where $A$ is the pre - exponential factor $\left[\mathrm{s}^{-1}\right], \Delta E$ is the activation energy [ $\mathrm{J}^{\text {mole }}{ }^{-1}$ ] and $R$ is universal gas constant $\left[\mathrm{J}\right.$ mole $\left.{ }^{-1} \cdot \mathrm{K}^{-1}\right]$. The criterion for tissue necrosis is $[1,5]$

$$
\theta(\mathbf{x}) \geq 1
$$


In current work the function $\theta$ in equation (3) is assumed as a polynomial in a form [1]

$$
f(\theta)=\sum_{j=1}^{3} m_{j} \theta^{j-1}
$$

where $m_{j}$ are the coefficients.

On the basis of the injury integral (4) the damage fraction is calculated as

$$
F_{D}(\mathbf{x})=1-\exp (-\theta)
$$

Equation (1) is supplemented by boundary conditions:

$$
\mathbf{x} \in \Gamma_{0}: \begin{cases}q(\mathbf{x}, t)=q_{0}, & t \leq t_{\text {exp }} \\ q(\mathbf{x}, t)=\alpha\left(T-T_{a m b}\right), & t>t_{\text {exp }}\end{cases}
$$

where $q_{0}\left[\mathrm{Wm}^{-2}\right]$ is the known irregular boundary heat flux (described as a polynomial function of $7^{\text {th }}$ degree, similar to (6)), $\alpha\left[\mathrm{Wm}^{-2} \mathrm{~K}^{-1}\right]$ is the convective heat transfer coefficient and $T_{a m b}$ is the temperature of surrounding, while $t_{\text {exp }}$ is the exposure time. Along the remaining parts of the boundary the non-flux condition is accepted

$$
\mathbf{x} \in \Gamma_{c}: \quad q(\mathbf{x}, t)=0
$$

and the initial distribution of temperature is also known

$$
t=0: \quad T(\mathbf{x}, t)=T_{p}
$$

\section{BOUNDARY ELEMENT METHOD}

The problem described by the equation (1) has been solved using the $1^{\text {st }}$ scheme of the BEM for 2D transient heat diffusion [2,7].

At first, the time grid has been introduced:

$$
0=t^{0}<t^{1}<\ldots<t^{f-1}<t^{f}<\ldots<\infty, \quad \Delta t=t^{f}-t^{f-1}
$$

If the 1 st scheme of the BEM is taken into account $[2,7]$ then the boundary integral equation corresponding to transition $t^{f-1} \rightarrow t^{f}$ is of the form

$$
\begin{gathered}
B(\xi) T\left(\mathbf{x}, t^{f}\right)+\frac{1}{c} \int_{t^{f-1}}^{t^{f}} \int_{\Gamma} T^{*}\left(\xi, \mathbf{x}, t^{f}, t\right) q(\mathbf{x}, t) \mathrm{d} \Gamma \mathrm{d} t= \\
\frac{1}{c} \int_{t^{f-1}}^{t^{f}} \int_{\Gamma} q^{*}\left(\xi, \mathbf{x}, t^{f}, t\right) T(\mathbf{x}, t) \mathrm{d} \Gamma \mathrm{d} t+\iint_{\Omega} T^{*}\left(\xi, \mathbf{x}, t^{f}, t^{f-1}\right) T\left(\mathbf{x}, t^{f-1}\right) \mathrm{d} \Omega+ \\
\frac{1}{c} \int_{t^{f-1}}^{t^{f}} \iint_{\Omega} Q_{V}(\mathbf{x}, t) T^{*}\left(\xi, \mathbf{x}, t^{f}, t\right) \mathrm{d} \Omega \mathrm{d} t
\end{gathered}
$$


In equation (12) $T^{*}$ is the fundamental solution [7]:

$$
T^{*}\left(\boldsymbol{\xi}, \mathbf{x}, t^{f}, t\right)=\frac{1}{4 \pi a\left(t^{f}-t\right)} \exp \left[-\frac{r^{2}}{4 a\left(t^{f}-t\right)}\right]
$$

where $r$ is the distance from the point under consideration $\mathbf{x}$ to the observation point $\xi$, while

$$
q^{*}\left(\xi, \mathbf{x}, t^{f}, t\right)=-\lambda T_{, i}^{*}\left(\xi, \mathbf{x}, t^{f}, t\right) n_{, i}, \quad q(\mathbf{x}, t)=-\lambda T_{, i}(\mathbf{x}, t) n_{, i}
$$

and $B(\xi)$ is the coefficient from the interval $(0,1)$.

The constant elements with respect to time have been used [7] and then the boundary integral equation (12) takes a form

$$
\begin{aligned}
& B(\xi) T\left(\mathbf{x}, t^{f}\right)+\int_{\Gamma} q\left(\mathbf{x}, t^{f}\right) g(\xi, \mathbf{x}) \mathrm{d} \Gamma=\int_{\Gamma} T\left(\mathbf{x}, t^{f}\right) h(\xi, \mathbf{x}) \mathrm{d} \Gamma \\
& +\iint_{\Omega} q^{*}\left(\xi, \mathbf{x}, t^{f}, t^{f-1}\right) T\left(\mathbf{x}, t^{f-1}\right) \mathrm{d} \Omega+\iint_{\Omega} Q_{V}\left(\mathbf{x}, t^{f-1}\right) g(\boldsymbol{\xi}, \mathbf{x}) \mathrm{d} \Omega
\end{aligned}
$$

where

$$
h(\xi, \mathbf{x})=\frac{1}{c} \int_{t^{f-1}}^{t^{f}} q^{*}\left(\xi, \mathbf{x}, t^{f}, t\right) \mathrm{d} t
$$

and

$$
g(\xi, \mathbf{x})=\frac{1}{c} \int_{t^{f-1}}^{t^{f}} T^{*}\left(\xi, \mathbf{x}, t^{f}, t\right) \mathrm{d} t
$$

In numerical realization the following discrete form of the boundary integral equation has been considered ( $N$ - number of boundary elements, $L$ - number of internal elements)

$$
\sum_{j=1}^{N} G_{i j} q_{j}^{f}=\sum_{j=1}^{N} H_{i j} T_{j}^{f}+\sum_{l=1}^{L} P_{i l} T_{l}^{f-1}+\sum_{l=1}^{L} Z_{i l} Q_{V l}^{f-1}
$$

where

$$
G_{i j}=\int_{\Gamma_{j}} g\left(\xi^{i}, \mathbf{x}\right) \mathrm{d} \Gamma_{j}
$$

and

$$
H_{i j}= \begin{cases}\int_{\Gamma_{j}} h\left(\xi^{i}, \mathbf{x}\right) \mathrm{d} \Gamma_{j}, & i \neq j \\ -0.5, & i=j\end{cases}
$$


while

$$
P_{i l}=\iint_{\Omega_{l}} T^{*}\left(\xi^{i}, \mathbf{x}, t^{f}, t^{f-1}\right) \mathrm{d} \Omega_{l}
$$

and

$$
Z_{i l}=\iint_{\Omega_{l}} g\left(\xi^{i}, \mathbf{x}\right) \mathrm{d} \Omega_{l}
$$

The system of equations (18) can be written in the matrix form, namely

$$
\mathbf{G} \cdot \mathbf{q}^{f}=\mathbf{H} \cdot \mathbf{T}^{f}+\mathbf{P} \cdot \mathbf{T}^{f-1}+\mathbf{Z} \cdot \mathbf{Q}_{\mathbf{V}}{ }^{f-1}
$$

After the determining the "missing" boundary values of temperatures and heat fluxes, the values of temperatures at the internal points $\xi^{i}$ for time $t^{f}$ are calculated using the formula $(i=N+1, \ldots, N+L)$ :

$$
T_{i}^{f}=\sum_{j=1}^{N} H_{i j} T_{j}^{f}-\sum_{j=1}^{N} G_{i j} q_{j}^{f}+\sum_{l=1}^{L} P_{i l} T_{l}^{f-1}+\sum_{l=1}^{L} Z_{i l} Q_{V l}^{f-1}
$$

\section{RESULTS OF COMPUTATIONS}

At the stage of numerical realization the $1^{\text {st }}$ scheme of boundary element method for constant elements has been applied [2,7].

The domain of rectangular shape (c.f. Fig. 1) of dimensions $0.05 \times 0.015$ [m]. The interior of domain has been divided into 6000 internal constant cells while the external boundary into 320 constant elements.

In computations, the following values of tissue parameters have been assumed: $\lambda=0.3$ $\left[\mathrm{Wm}^{-1} \mathrm{~K}^{-1}\right], c=3.647\left[\mathrm{MJ} \mathrm{m}^{-3} \mathrm{~K}^{-1}\right], G_{B 0}=0.00125\left[\left(\mathrm{~m}^{3} \mathrm{blood} / \mathrm{s}\right) /\left(\mathrm{m}^{3}\right.\right.$ tissue $\left.)\right], Q_{m e t}=245$ $\left[\mathrm{Wm}^{-3}\right]$, while for the blood $c_{B}=3.9962\left[\mathrm{MJ} \mathrm{m}^{-3} \mathrm{~K}^{-1}\right]$ and $T_{B}=37{ }^{\circ} \mathrm{C}$ [5]. The parameters of Arrhenius injury integral are: $A=3.1 \cdot 10^{98}\left[\mathrm{~s}^{-1}\right], \Delta E=6.27 \cdot 10^{5}\left[\mathrm{~J} \mathrm{~mole}^{-1}\right]$ and $R=8.314$ $\left[\mathrm{J}\right.$ mole ${ }^{-1} \mathrm{~K}^{-1}$ ], and the coefficients appearing in the $f(\theta)$ function are as follows [1]:

$$
\begin{aligned}
& 0<\theta \leq 0.1: \quad m_{1}=1, \quad m_{2}=25, \quad m_{3}=-260 \\
& 0.1<\theta \leq 1: \quad m_{1}=1, \quad m_{2}=-1, \quad m_{3}=0
\end{aligned}
$$

The values of these coefficients for the interval from 0 to 0.1 respond to the increase of perfusion rate caused by vasodilatation, while for interval from 0.1 to 1 they reflect blood flow decrease as the vasculature begins to shut down (thrombosis).

In the boundary condition (c.f. equation (8)) the following values of parameters have been assumed: $\alpha=10\left[\mathrm{Wm}^{-2} \mathrm{~K}^{-1}\right]$ and $T_{a m b}=20{ }^{\circ} \mathrm{C}$. Two cases of heat flux $q_{0}$ and exposure time $t_{\text {exp }}$ have been considered. Time step $\Delta t=1[\mathrm{~s}]$.

In example 1 the maximal value of the heat flux $q_{0}$ is assumed as $40\left[\mathrm{~kW} \mathrm{~m}^{-2}\right]$ while 
the exposure time is 10 seconds. The results of computation are presented in Fig. 2. The temperature, tissue injury integral $\theta$ and perfusion coefficient $G_{B}$ distribution in the domain considered for selected moments of time are presented.
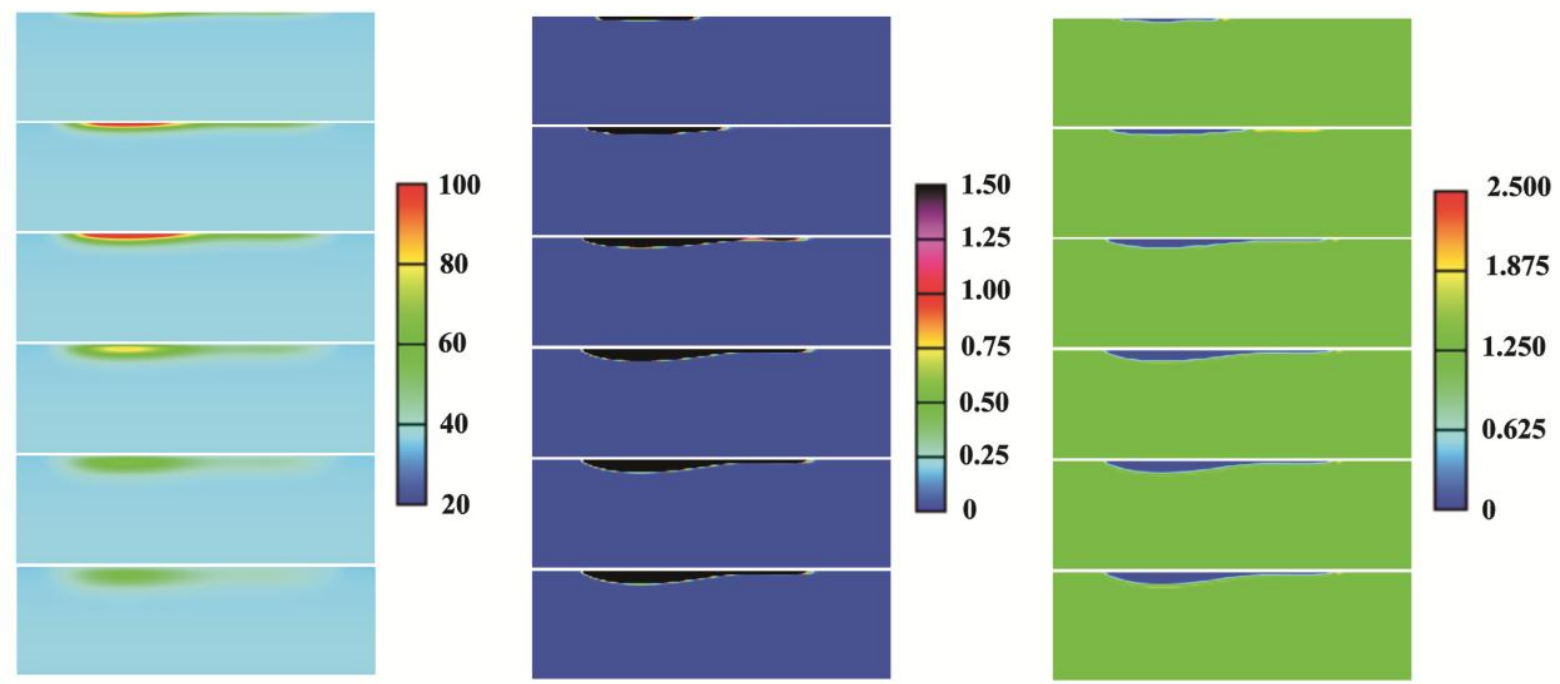

Figure 2. Example 1: distribution of temperature $\left[{ }^{\circ} \mathrm{C}\right]$, tissue injury integral and perfusion coefficient $G_{B}\left[\left(\mathrm{~m}^{3} \mathrm{blood} / \mathrm{s}\right) /\left(\mathrm{m}^{3}\right.\right.$ tissue $\left.)\right] \times 1000$ for $2,5,8,11,14$ and $17[\mathrm{~s}]$

In example 2 the maximal value of the heat flux $q_{0}$ is equal $20\left[\mathrm{~kW} \mathrm{~m}^{-2}\right]$ and $t_{\text {exp }}=30$ seconds. As previously, the results obtained for distribution of temperature, tissue injury integral $\theta$ and perfusion coefficient $G_{B}$ for selected time steps are presented in figure 3.
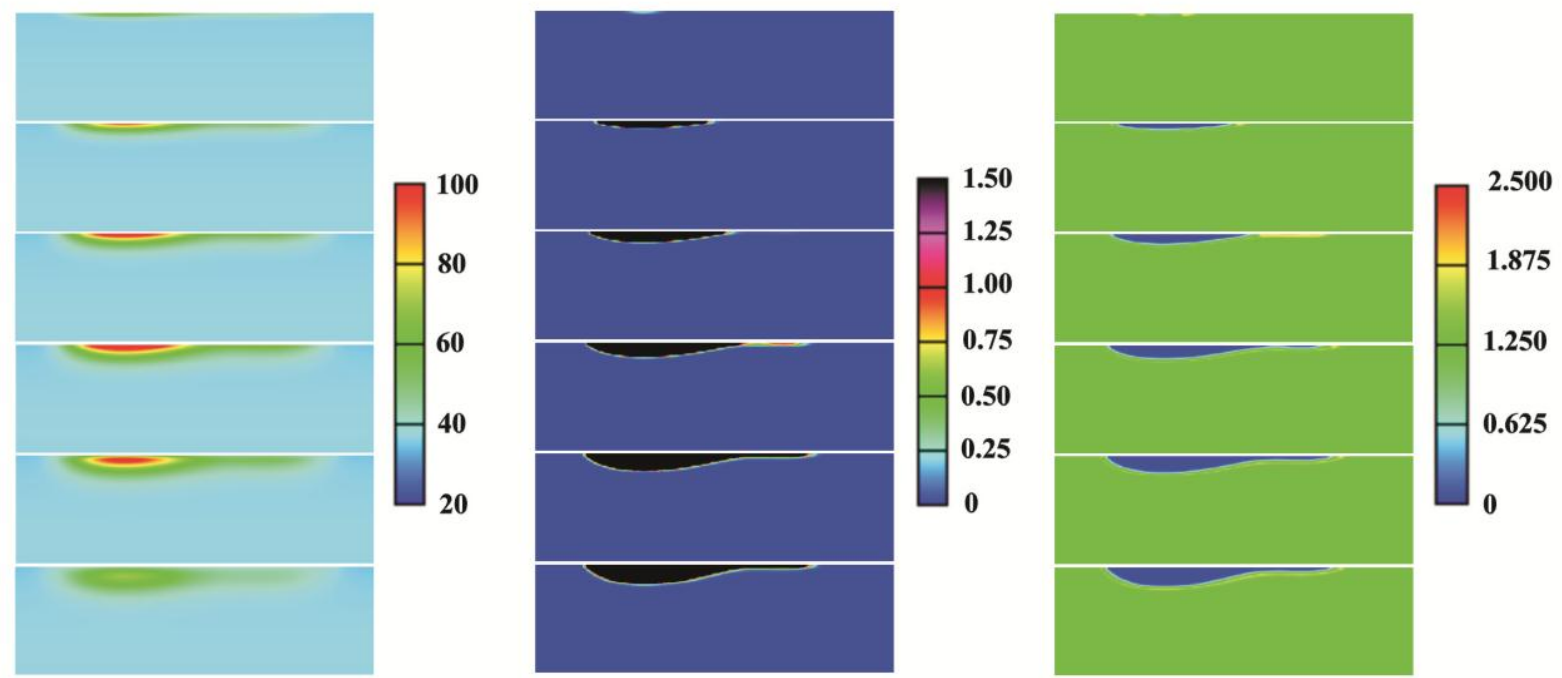

Figure 3. Example 2: distribution of temperature $\left[{ }^{\circ} \mathrm{C}\right]$, tissue injury integral and perfusion coefficien $G_{B}\left[\left(\mathrm{~m}^{3}\right.\right.$ blood $\left./ \mathrm{s}\right) /\left(\mathrm{m}^{3}\right.$ tissue $\left.)\right] \times 1000$ for $2,9,16,23,30$ and 37 [s] 
The analysis of the dynamics of burn wound formation process is based on the damage fraction $F_{D}$ (c.f. equation (7)). Five intervals of values for $F_{D}$ have been distinguished (for the sake of convenience denoted as tha):

- tha $1:[0,0.01)$

- tha $2:[0.01,0.05)$

- tha $3:[0.05,0.63)$

- tha $4:[0.63,0.99)$

- tha $5: \geq 0.99$

The values in intervals are interpreted as:

- 0.01: up to this value the tissue is in its normal state, so the value could be named as the border of thermally untouched tissue,

- 0.05: the border of vasodilatation - arise from the polynomial function for $G_{B}$ (c.f. equations (3), (6) and (25)); at this value of $F_{D}$ the perfusion rate has maximum,

- 0.63: corresponds to criterion of tissue necrosis (c.f. equation (5)),

- 0.99: could be treated as the criterion of complete tissue destruction.

In the figures 4 and 5 the numbers of elements achieving individual intervals in selected time intervals are presented. It should be pointed out that these data could be very easy recalculated into cross-section area of the wound using the field of single internal element (for the geometrical grid assumed in the paper: $1.25 \cdot 10^{-7}\left[\mathrm{~m}^{2}\right]$ ).

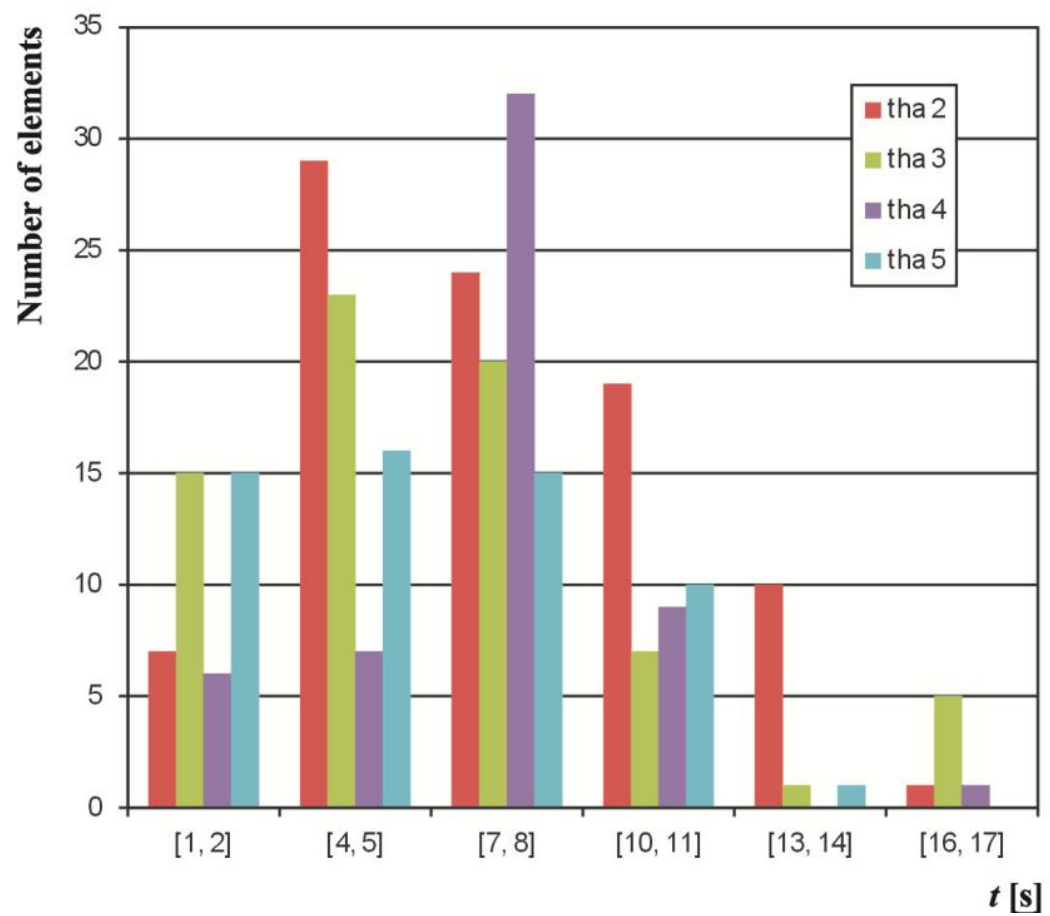

Figure 4. Example 1: Number of elements achieving individual intervals 


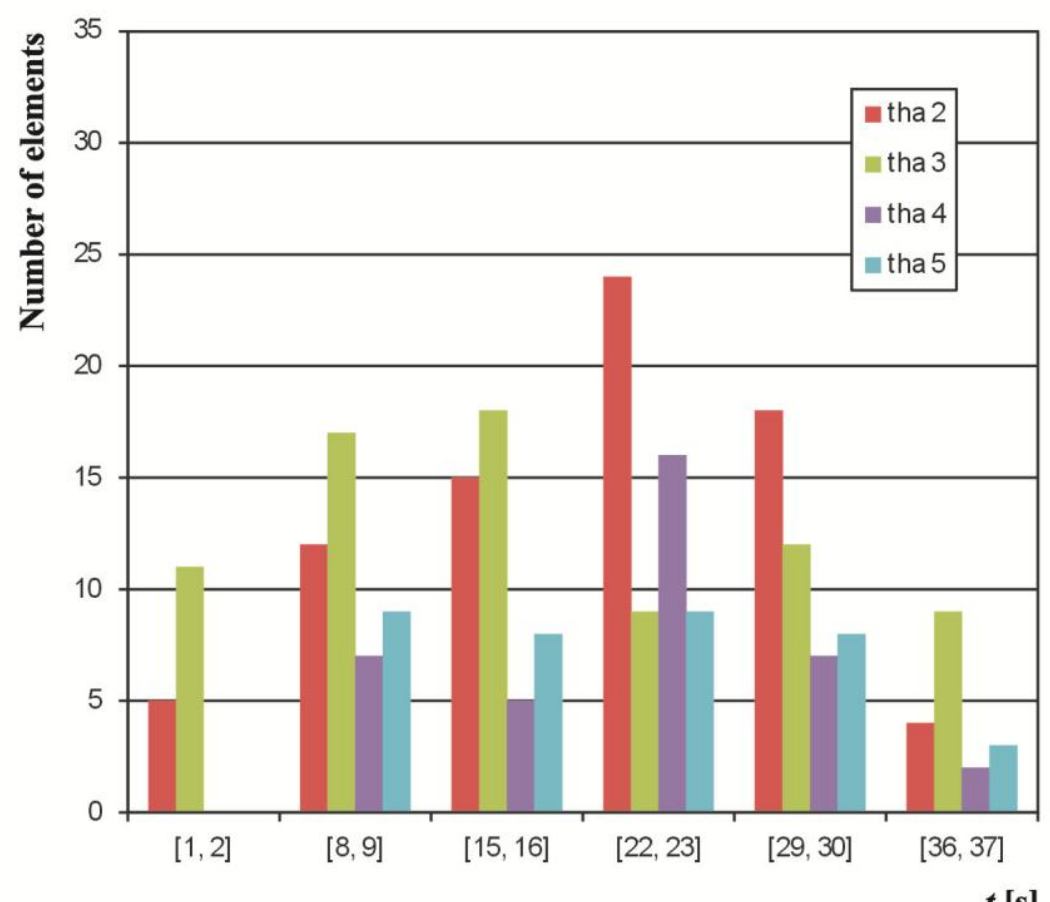

Figure 5. Example 2: Number of elements achieving individual intervals

Summarizing the number of elements which swapped from one interval to another one in successive time intervals we can obtain knowledge of the dynamics of the wound formation process. These results are presented in the figure 6 while in figure 7 the comparison of the proliferation of the burn wound in both examples is shown.

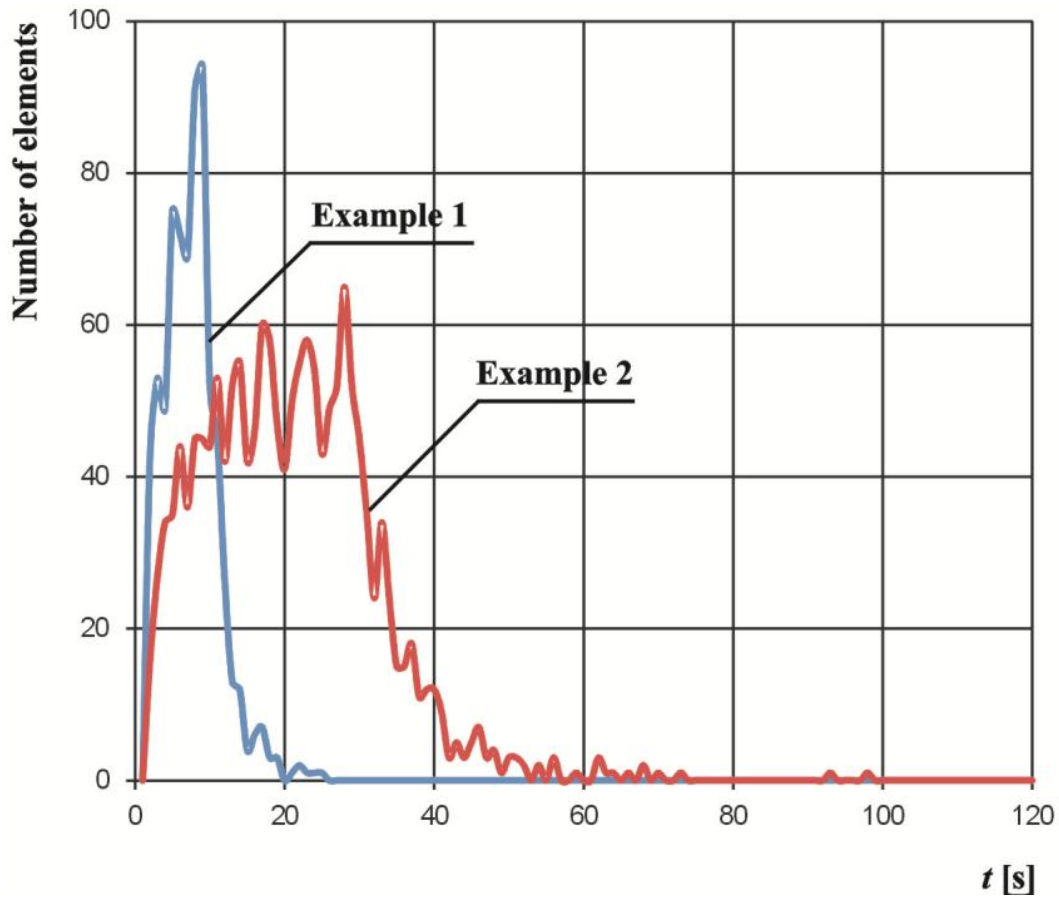

Figure 6. The burn wound formation process 


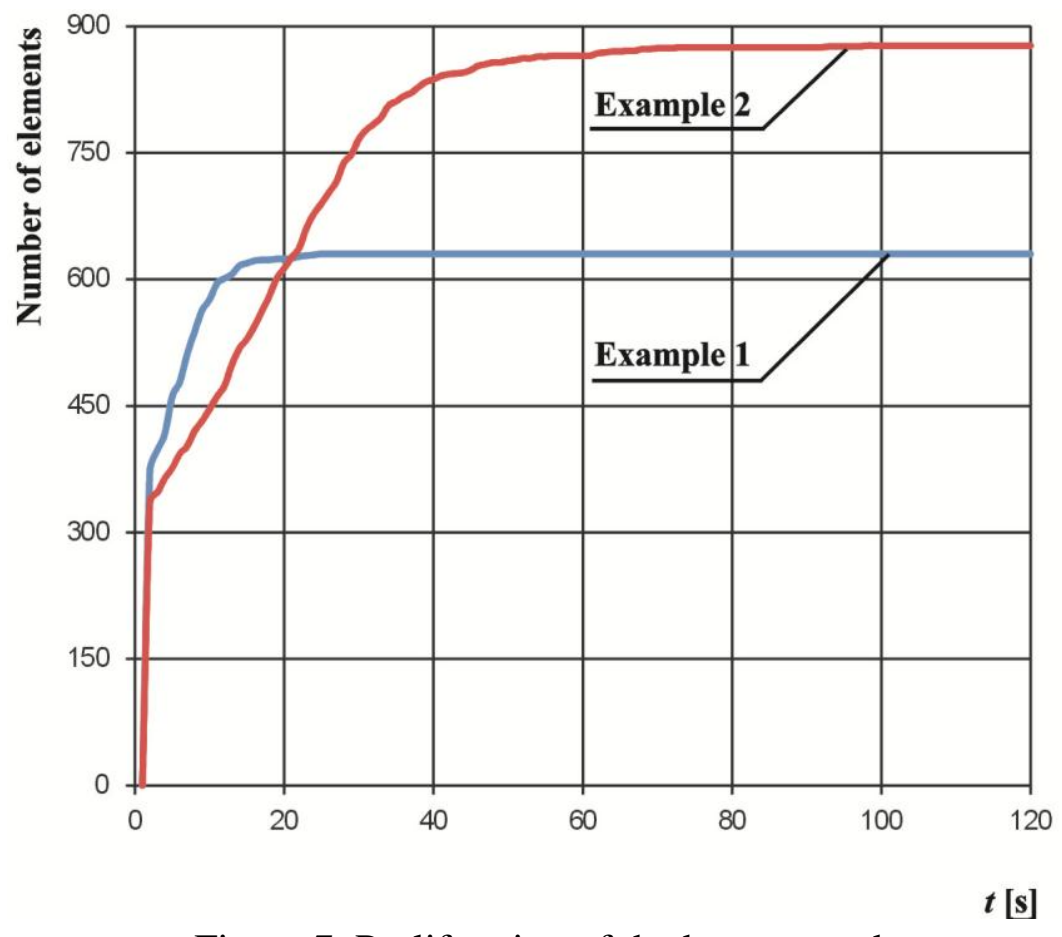

Figure 7. Proliferation of the burn wound

\section{FINAL REMARKS}

The influence of temperature on the value of Arrhenius injury integral and blood perfusion rate is clearly visible. According to the necrotic changes in the tissue domain the perfusion coefficient is changing, decreasing to zero for the region in which the injury integral is equal or greater than 1 (c.f. equation (5)).

Comparing the two examples analyzed in the paper, one can note that in the second example the burn wound is greater although the maximal value for external heat flux is smaller than in the $1^{\text {st }}$ example. The reason of that is the greater value of exposure time. In both cases one can say that, from thermal point of view the burn wound is formed within time less that 2 minutes (see: figures 6 and 7).

The value of damage fraction $F_{D}$ less than 0.05 means that that tissue could regain into its natural (heal) state, so the model should take into consideration also possibility of decreasing of damage fraction and perfusion coefficient as well.

Because widespread problem in modeling of bioheat transfer is associated with the difference in values of individual parameters, the method of sensitivity analysis should be taken into account.

\section{Acknowledgements}

This paper is part of project NR-13-0124-10/2010. 


\section{REFERENCES}

[1] Abraham J. P., Sparrow E. M., "A thermal-ablation bioheat model including liquid-to vapor phase change, pressure- and necrosis-dependent perfusion, and moisturedependent properties". Int. Journal of Heat and Mass Transfer, 50, 2537-2544, 2007.

[2] Brebia C. A., Dominquez J., „Boundary elements, an introductory course”. Computational Mechanics Publications, McGraw-Hill Book Company, Londyn, 1992.

[3] Glenn T. N., Rastegar S., Jacques S. L., "Finite element analysis of temperature controlled coagulation in laser irradiated tissue". IEEE Transactions on Biomedical Engineering, 43, 79-87, 1996.

[4] Henriques F. C., "Studies of thermal injuries, V. The predictability and the significance of thermally induced rate process leading to irreversible epidermal injury". Archives of Pathology, 43, 489-502, 1947.

[5] Jasiński, M., "Sensitivity analysis of transient bioheat transfer with perfusion rate dependent on tissue injury". Computer Assisted Mechanics and Engineering Science, 16, $267-277,2009$.

[6] Jasiński M., "Modelling of tissue heating process". Ph.D. Thesis, Silesian University of Technology, Gliwice, 2001 (in Polish).

[7] Majchrzak E., "Boundary element method in heat transfer". Publ. of Czestochowa University of Technology, Czestochowa, 2001 (in Polish).

[8] Majchrzak E., Jasiński M., "Numerical analysis of bioheat transfer processes in tissue domain subjected to a strong external heat source". In: Z. Yao, M.H. Aliabadi, eds., Boundary Elements Techniques, Tsinghua University Press, Springer, 2002.

[9] Majchrzak E., Mochnacki B., Jasiński M., "Numerical modelling of bioheat transfer in multi-layer skin tissue domain subjected to a flash fire". Computational Fluid and Solid Mechanics, 2, Elsevier, 2003.

[10] Oden J. T., Diller K. R., Bajaj C., Browne J. C., Hazle J., Babuska I., Bass J., Biduat L., Demkowicz L., Elliott A., Feng Y., Fuentes D., Prudhomme S., Rylander M. N., Stafford R. J., Zhang Y., "Dynamic data-driven finite element models for laser treatment of cancer". Numerical Methods for Partial Differential Equations, 23, 904-922, 2007. 